\title{
Strategic influences on recollection in the exclusion task: Electrophysiological evidence
}

\author{
JANE E. HERRON and MICHAEL D. RUGG \\ University College London, London, England
}

\begin{abstract}
One assumption underlying the use of the exclusion task as part of the process dissociation procedure is that studied items are successfully excluded only when they are recollected. The present study employed event-related potentials (ERPs) to demonstrate that successful exclusion does not necessarily require recollection. In two experiments, the study tasks for to-be-excluded items were identical, but the tasks employed with target items differed, giving better memory for these items in Experiment 1 than in Experiment 2. Successfully excluded items elicited the ERP signature for recollection-the left parietal old/new effect - in Experiment 2 only. These findings indicate that the subjects adopted different retrieval strategies in the two experiments. It is suggested that they made more use of source information about to-be-excluded items in the second experiment than in the first.
\end{abstract}

In the dual-process framework, recognition memory is fractionated into two processes, recollection and familiarity (Gardiner \& Java, 1993; Jacoby, 1991; Mandler, 1980). Recollection is defined as recognition accompanied by retrieval of contextual information from the encoding episode. Familiarity is held to be acontextual, fast acting, and relatively automatic. To separately estimate the contributions of familiarity and recollection, Jacoby introduced the process dissociation procedure. With this procedure, memory for study items is tested in two tasks, an inclusion task and an exclusion task. In the inclusion task, subjects are required to endorse all studied items as old, regardless of source, while rejecting new items. It is assumed that studied items will be correctly classified whether recognized on the basis of recollection or familiarity. Exclusion instructions direct subjects to make a positive recognition judgment for old items belonging to a specific source (hereafter referred to as targets), while rejecting both unstudied items and old items belonging to an alternative source (hereafter referred to as nontargets). It is assumed that nontargets will be successfully excluded if information about their study source is recollected, whereas nontargets recognized on the basis of familiarity alone will intrude as errors. If it is further assumed that the probabilities of recognizing a nontarget on the basis of familiarity and recollection are independent and do not vary between the inclusion and the exclusion tasks, these probabilities can be estimated by combining the nontarget performance measures from each task.

The authors and their research are supported by the Wellcome Trust. We thank three anonymous reviewers for their comments on an earlier version of this paper. Correspondence concerning this article should be addressed to M. D. Rugg, Center for the Neurobiology of Learning and Memory, University of California, Irvine, CA 9267-3800 (e-mail: mrugg@uci.edu).
As was noted, a key assumption underlying the use of the exclusion task is that subjects employ recollection to reject nontarget items. It is not obvious, however, that this is always necessary for successful performance. In principle, subjects could elect to endorse an item as a target only if its recognition is accompanied by the appropriate source-specifying information, rejecting any item for which such information is unavailable. Under these circumstances, recollection of the source of a nontarget would not be necessary for it to be successfully excluded, even if its familiarity were high. Rather, the item would be excluded on the basis of its failure to elicit information diagnostic of the target source. In the study reported below, we employed an electrophysiological measureevent-related potentials (ERPs) - in an attempt to demonstrate that subjects may indeed exclude nontargets without recollecting their encoding context.

ERP studies of recognition memory have identified possible neural correlates of both recollection and familiarity (Curran, 2000; Rugg et al., 1998). The putative ERP correlate of familiarity takes the form of greater positivity for items attracting an old response than for items attracting a new response and is maximal at midfrontal scalp sites between approximately 300 and $500 \mathrm{msec}$. The putative ERP correlate of recollection, the focus of the present study, also takes the form of greater positivity for correctly identified old items, relative to correctly identified new items, but this positivity has a left temporo-parietal scalp maximum and onsets around $400-500$ msec poststimulus. A variety of evidence links the left parietal old/new effect to recollection (for reviews, see Friedman \& Johnson, 2000; Rugg \& Allan, 2000). For example, the effect is greater when elicited by recognized items attracting correct, rather than incorrect, source judgments (Trott, Friedman, Ritter, Fabiani, \& Snodgrass, 1999; Wilding, 2000; Wilding \& Rugg, 1996), items attracting remember, as opposed to know, judg- 
ments (Duzel, Yonelinas, Mangun, Heinze, \& Tulving, 1997; Smith, 1993; Trott et al., 1999; but see Spencer, Vila Abad, \& Donchin, 2000), and items judged old on the basis of recollection and familiarity, rather than on the basis of familiarity alone (Curran, 2000; Rugg, Herron, \& Morcom, 2002). In addition, the effect is absent in neurological patients in whom recollection is impaired (Duzel, Vargha-Khadem, Heinze, \& Mishkin, 2001; Tendolkar et al., 1999).

On the assumption that the left parietal old/new effect is a correlate of recollection-based recognition, ERPs can be used to test the assumption that nontargets in an exclusion task must be recollected to be excluded. Specifically, if this assumption is correct, these items should elicit a left parietal effect when they are correctly excluded. Wilding and Rugg (1997) recorded ERPs during an exclusion task in which subjects responded positively to items spoken at study in one voice and to excluded items that had been spoken in an alternative voice. Reliable left parietal effects were found for both targets and nontargets, although the effect for nontargets was only about half the size of that elicited by targets (Wilding \& Rugg, 1997). Cycowicz, Friedman, and Snodgrass (2001) also found a significant parietal positivity for both targets and nontargets in an exclusion task involving pictures that were studied in one of two colors (Cycowicz et al., 2001). However, in another study employing an exclusion condition, no parietal effect was observed for nontargets (Dywan, Segalowitz, \& Webster, 1998). In the test phase of this experiment, previously studied words (targets) were presented along with foils, some of which were repeated after a lag of only a few trials (nontargets). Whereas a parietal effect was observed for targets, no effect was detected for excluded nontargets. This striking finding (see Dywan, Segalowitz, \& Arsenault, 2002, and Dywan, Segalowitz, Webster, Hendry, \& Harding, 2001, for replications) suggests that there may be circumstances in which subjects are in some sense able to "inhibit" or "suppress" recollection of nontarget items in exclusion tasks.

In the present study, ERPs were recorded in two sequentially conducted experiments. In each case, lists of visually presented words were presented in two separate study blocks, each associated with a different study task. The task employed in the first (nontarget) block was identical in the two experiments, whereas the study tasks employed in the second (target) block differed; the task in Experiment 1 gave rise to good memory for targets, whereas that in Experiment 2 led to poorer memory for these items. In both experiments, the subjects were required to endorse target items as old while rejecting nontarget and unstudied (new) items. To anticipate the results, in Experiment 1, we found that ERPs elicited by correctly excluded nontargets failed to elicit a left parietal old/new effect. This finding is at odds with those of Wilding and Rugg (1997) and Cycowicz et al. (2001) but is consistent with those of Dywan et al. (2002; Dywan et al., 1998; Dywan et al., 2001). As will be elaborated in the Discussion section, we hypothesized that the absence of a nontarget left parietal effect in our first experiment reflected the ease with which the subjects were able to recollect the targets. In Experiment 2, we tested this hypothesis by reducing the probability of target recollection, so that the failure of an item to elicit recollection of the target source was no longer a reliable basis for its classification as a nontarget. We predicted that, under these circumstances, excluded nontargets would elicit a left parietal effect, since to optimize performance, it would now be necessary to attempt to recollect both target and nontarget source information. Thus, the question was whether, despite having been encoded in an identical fashion, nontargets would elicit left parietal effects that differed in magnitude according to the level of target memory.

\section{METHOD}

\section{Subjects}

All the subjects were right-handed, had English as their first language, and were 18-30 years of age (mean, 22). The two experiments were conducted over a 4-month period, and the subjects were, in each case, drawn from the same population of UCL undergraduate and graduate students. Twenty subjects participated in Experiment 1. Data from 4 of the subjects were discarded because there were fewer than 16 trials in one of the critical conditions, leaving 9 females and 7 males. Seventeen subjects, none of whom had taken part in the first experiment, participated in Experiment 2. Sixteen of these subjects ( 8 female) contributed ERPs with sufficient trials. All the subjects gave informed consent before participation in the study.

\section{Stimuli}

The same stimulus set was employed in both experiments. Critical stimuli consisted of 240 concrete nouns, which were divided into three lists of 80 items each. There were 90 additional filler words. All words were between four and nine letters in length and had a frequency of between 30 and 100 counts per million (Kučera \& Francis, 1967). Nontarget lists contained 80 words interspersed among 82 fillers. Target lists consisted of 80 critical words, with 2 filler words added to the beginning of each list. Each test list contained 240 critical items. Eighty test items were drawn from the nontarget study block, 80 belonged to the target study block, and a further 80 were new. ${ }^{1}$ Two fillers were added to the beginning of each test list, and a further 2 fillers were added after both the 82nd and the 164th items.

Three test sequences were created, consisting of different orderings of the 240 critical items and associated fillers. These sequences were rotated across subjects, as were the lists supplying the nontarget, target, and new items.

\section{Procedure}

Prior to the experiment, the subjects were fitted with an electrode cap (see below). The subjects were seated in a sound-attenuated recording booth, facing a display monitor, with the index fingers of each hand resting on response keys. An interval of around 5 min separated each phase of the experiment. Throughout the experiment, the stimuli were presented in central vision (white uppercase letters on a black screen) at the same point as a fixation character. The stimuli subtended a vertical visual angle of $0.4^{\circ}$ and a maximum horizontal angle of $1.5^{\circ}$.

In both experiments, study trials were initiated by an experimentercontrolled mouse click. Each trial consisted of the presentation for $100 \mathrm{msec}$ of a fixation character $(*)$, followed by a 122 -msec period in which the screen was blanked. The stimulus was then presented for $600 \mathrm{msec}$ and was replaced by a blank screen. On each trial of the nontarget block, the subjects were required to incorporate the pre- 
sented word into a sentence and to say the sentence aloud. The task performed during the target study block varied between experiments: In Experiment 1, the requirement was to verbally rate each item for pleasantness on a 5-point scale, whereas in Experiment 2, the subjects were instructed merely to read each item aloud. These tasks were selected on the basis of pilot testing, which indicated that they gave rise to a robust difference in subsequent recognition memory.

The test procedure was identical in each experiment. Each trial consisted of the presentation of the fixation character for $100 \mathrm{msec}$, followed by a $122-\mathrm{msec}$ period in which the screen was blanked. The test item then appeared for a duration of $600 \mathrm{msec}$, after which the screen was blanked for $4,400 \mathrm{msec}$. Brief rest intervals were provided after the 82 nd and 164th trials. The task was to respond with one hand to items from the second (target) study block and with the other hand to any other item, regardless of whether it was old or new. The subjects were informed that if they saw a word that had been presented in the first study block, they could be certain that it had not been presented in the subsequent block. The hand employed for each response was counterbalanced across subjects.

\section{ERP Recording and Analysis}

EEG was recorded from 31 silver/silver-chloride electrodes, 29 of which were embedded in an elastic cap (these 29 sites were a subset of the montage 10 provided by the supplier of the electrode cap; see http://www.easycap.de/ easycap/english/schemae.htm and Figure 1A). The remaining two electrodes were placed on right and left mastoid processes. Recording parameters, artifact rejection criteria, and the blink correction method employed were as described previously (Maratos \& Rugg, 2001). ERPs (epoch length, 1,536 msec, beginning $102 \mathrm{msec}$ prestimulus) were formed for three response categories: correctly classified target items, correctly excluded nontargets, and correctly classified new items.

\section{RESULTS}

For the sake of brevity and to permit direct comparison of their findings, the data from the two experiments are presented and analyzed together. $F$ ratios for factors
$\mathbf{A}$

\section{LEFT}

\section{RIGHT}

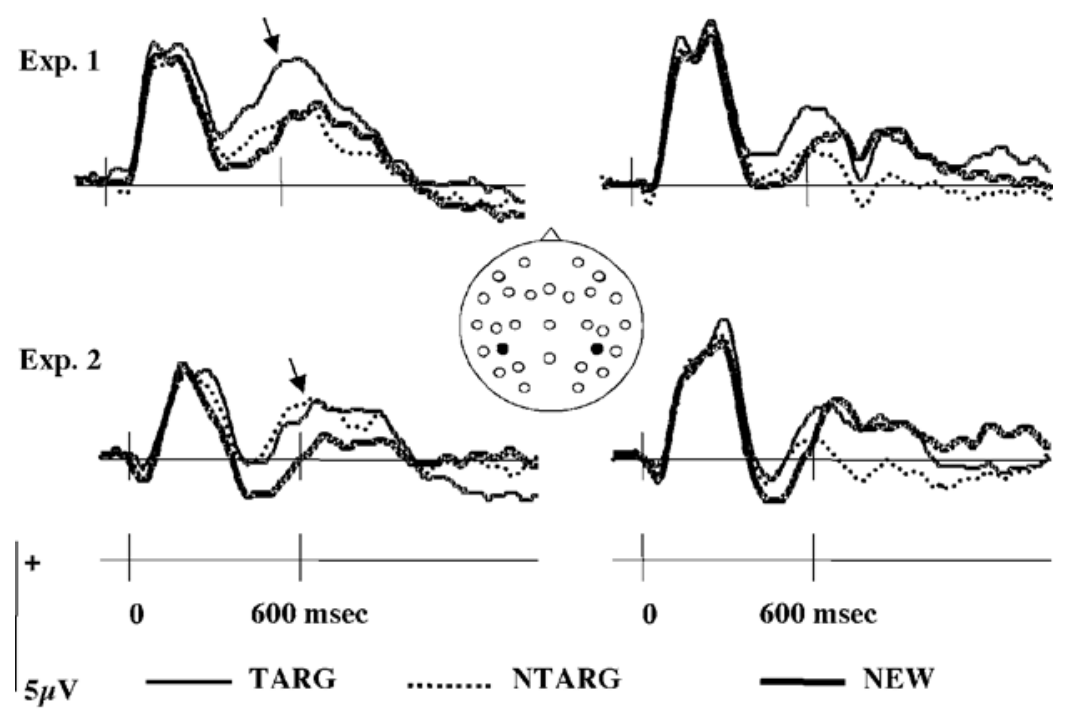

B

TARG-NEW

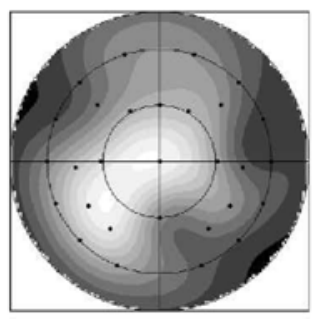

\section{TARG-NTARG}

EXP. 1

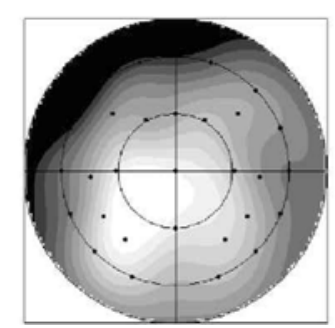

NTARG-NEW

EXP. 2

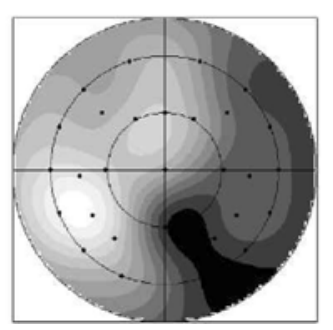

Figure 1. (A) Grand average waveforms elicited in each experiment by targets, nontargets, and new words at left and right parietal sites. The location of these sites are marked black on the central map indicating the recording montage employed. The left parietal old/new effect is indicated by arrows. (B) Voltage maps showing (from left to right) the scalp distributions in the 500- to $800-\mathrm{msec}$ latency range of the target old/new effect (collapsed across experiments), the target/nontarget effect in Experiment 1, and the nontarget old/new effect in Experiment 2. Each map is proportionately scaled according to the minimum and maximum amplitudes of the effect depicted. 
with more than two levels are reported with degrees of freedom corrected for sphericity violation (Greenhouse $\&$ Geisser, 1959). An alpha level of .05 was used for all statistical tests.

\section{Behavioral Performance}

Accuracy and reaction time (RT) data are displayed in Table 1. An analysis of variance (ANOVA) of the accuracy data gave rise to an interaction between experiment and response category $[F(1.5,45.5)=4.47, p<.025]$. Planned pairwise comparisons indicated that target accuracy was lower in Experiment 2 than in Experiment 1 $[F(1,30)=6.37, p<.025]$, as was accuracy for new items $[F(1,30)=6.45, p<.025]$. Accuracy for nontargets did not vary significantly $(F<1)$. An ANOVA of RTs revealed a main effect of condition $[F(2,59.3)=25.61, p<$ $.001]$. Pairwise comparisons indicated that both targets and nontargets attracted longer RTs than did new items $[F(1,30)=32.47, p<.001$, and $F(1,30)=40.16, p<.001$, respectively]. Target and nontarget RTs did not differ significantly.

\section{ERPs}

The mean numbers of trials (range in parentheses) contributing to the ERPs associated with targets, nontargets, and new items were 51 (17-71), 53 (33-66), and 65 (36-75) in Experiment 1 and 41 (26-60), 49 (34-71), and 53 (33-77) in Experiment 2. Grand average waveforms from left and right parietal electrodes are shown in Figure 1A. In Experiment 1, an increased positivity is evident over the left parietal scalp for ERPs to targets, relative to new items, but not for ERPs to nontargets. By contrast, in Experiment 2, both classes of studied items elicited greater left parietal positivity than did new items. Over the right parietal scalp, the old/new effects elicited by the targets in both experiments were greatly diminished, whereas the nontarget ERPs exhibited a sustained negative-going wave.

Left parietal effects were quantified by measuring the mean amplitude (relative to the mean of the prestimulus baseline) between 500 and $800 \mathrm{msec}$ poststimulus onset at the left parietal electrode indicated in Figure 1A. This site corresponds closely to that at which these effects are typically found to be at their maximum and is where the

Table 1

Accuracy and Reaction Time (RT, in Milliseconds) Data Associated With Correctly Classified Targets, Nontargets, and New Items in Experiments 1 and 2

\begin{tabular}{lcccc}
\hline Item Type & $P$ & $S D$ & RT & $S D$ \\
\hline \multicolumn{5}{c}{ Experiment 1 } \\
Targets & .76 & .16 & 1,578 & 573 \\
Nontargets & .83 & .06 & 1,673 & 588 \\
New & .96 & .05 & 1,366 & 501 \\
\multicolumn{5}{c}{ Experiment 2 } \\
Targets & .63 & .13 & 1,619 & 526 \\
Nontargets & .84 & .08 & 1,571 & 559 \\
New & .88 & .11 & 1,356 & 661 \\
\hline
\end{tabular}

effects were, in fact, maximal in the present experiments. The latency region employed to quantify the effect is the same as that employed in several previous studies (e.g., Donaldson \& Rugg, 1999; Schloerscheidt \& Rugg, 1997; Wilding \& Rugg, 1996). The magnitude and variability of the old/new effects from both the left parietal site and the homotopic right-hemisphere site are illustrated in Figure 2.

An ANOVA (employing the factors of experiment and item type [target, nontarget, or new]) of the amplitude data from the left parietal electrode revealed a significant effect of item type $[F(1.6,48.5)=12.16, p<.001]$ and an interaction between item type and experiment $[F(1.6,48.5)=4.81, p<.05]$. A subsidiary ANOVA for targets and new items gave rise to a main effect of item type $[F(1,30)=16.29, p<.001]$, with no sign of an interaction between item type and experiment $(F<1)$. These findings indicate that a left parietal effect was elicited by targets in both experiments $[F(1,15)=7.26, p<.05$, and $F(1,15)=10.32, p<.01$, for the target-new contrasts in Experiments 1 and 2, respectively] and that the effect was of equivalent magnitude in each case. By contrast, an ANOVA of the data for nontargets and new items revealed both an effect of item type $[F(1,30)=10.97, p<$ $.005]$ and an interaction between item type and experiment $[F(1,30)=8.20, p<.01]$, indicating that the size of the left parietal effect differed between experiments. Subsidiary ANOVAs showed that left parietal amplitudes for nontargets and new items did not differ in Experiment $1(F<1)$ but that left parietal ERPs to nontargets were significantly more positive than those to new items in Experiment $2[F(1,15)=22.80, p<.001]$. Finally, as would be expected from Figures 1A and 2, target and nontarget amplitudes differed significantly in Experiment $1[F(1,15)=15.04, p=.001]$, but not in Experiment 2 $(F<1){ }^{2}$

The foregoing analyses indicate that the nontarget left parietal effect varied in magnitude between experiments, whereas the effect elicited by targets did not. As is evident from Figure 1A, the ERPs elicited by nontargets at the right parietal site contained a sustained negativity (cf. Wilding \& Rugg, 1997). If this negativity had been greater in Experiment 1 than in Experiment 2, it could be argued that the apparent differences between experiments in the amplitude of the nontarget left parietal effect were merely a consequence of differential overlap between this effect and the opposing, right-maximal, negativity. We assessed this possibility with an ANOVA of the 500- to 800-msec latency region of the ERPs elicited by nontargets and new items at the right parietal site indicated in Figure 1A. The ANOVA revealed only a trend toward an effect of item type $[F(1,30)=3.18, p<$ $.1]$ and no sign of an interaction between item type and experiment $(F<1)$. Thus, the difference in magnitude of the nontarget left parietal effect in the two experiments likely cannot be attributed to changes in the amplitude of the right parietal negativity elicited by these items.

Figure 1B illustrates the scalp distributions of the target and nontarget old/new effects, as well as the distrib- 
LEFT

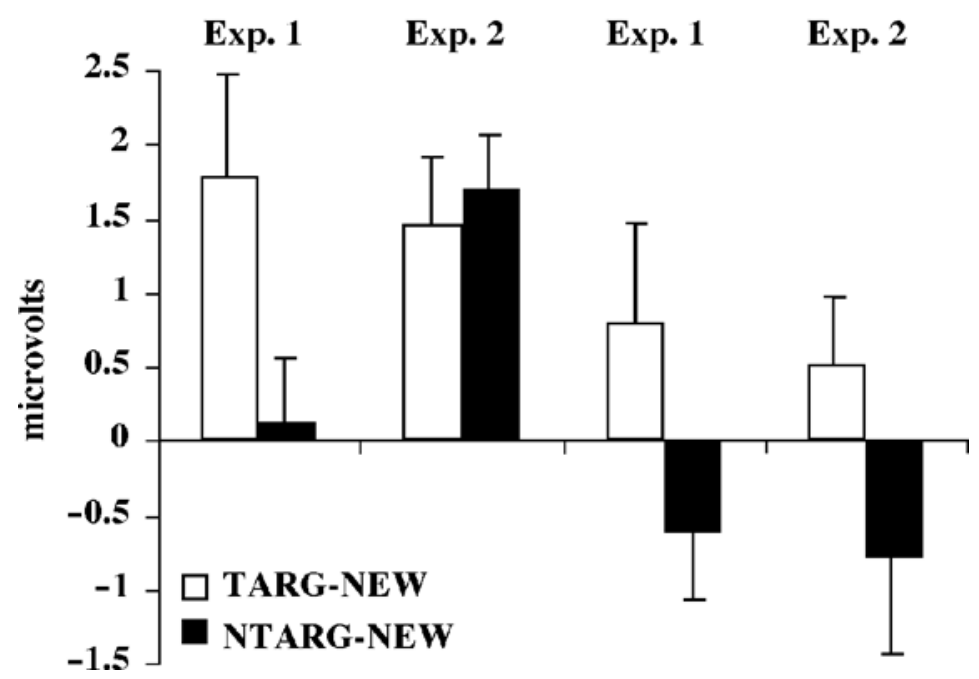

Figure 2. Mean amplitudes (and standard errors) of target and nontarget old/new effects in Experiments 1 and 2 at left and right parietal sites in the 500to 800 -msec latency region.

ution of the difference between target and nontarget ERPs in Experiment 1. The figure demonstrates that, in every case, the effects exhibit the left posterior distribution characteristic of the left parietal old/new effect (Rugg \& Allan, 2000). In separate ANOVAs, contrasts were performed between the scalp distributions of (1) the old/new effects elicited by targets in each experiment, (2) the target old/new effect and the target-nontarget effect in Experiment 1, and (3) the target and nontarget old/new effects in Experiment 2. The ANOVAs were conducted on data from all 29 electrode sites after rescaling, to eliminate possible confounds arising from differences in the magnitude of the effects being contrasted (McCarthy \& Wood, 1985); differences in scalp distribution are indicated by a significant interaction between condition and electrode site. For the first two of the aforementioned contrasts, this interaction was not significant $[F<1$ and $F(3.9,58.7)=2.26$, respectively $]$. These findings suggest that the ERP differences being contrasted reflected differential activity in a common population of generators. The ANOVA contrasting the target and the nontarget old/new effects in Experiment 2 did give rise to a condition $\times$ site interaction $[F(4.3,64.2)=$ $3.65, p<.01]$. This reflected the tendency for the nontargets, but not the targets, to elicit a reversed old/new effect over the right posterior scalp (see Figure 1B).

\section{DISCUSSION}

Consistent with previous research (Wilding \& Rugg, 1997), in both experiments, correctly classified target items elicited robust left parietal old/new ERP effects, suggesting that a substantial proportion of these items were endorsed on the basis of recollection (see the intro- duction). By contrast, the ERPs elicited by nontargets differed dramatically across the two experiments. In Experiment 1, nontarget ERPs failed to show a reliable left parietal effect, whereas nontargets in Experiment 2 elicited an effect comparable in size to that observed for targets. Since both the items and the encoding task employed in the nontarget study block were identical in the two experiments, these differential ERP effects are most likely attributable to the between-experiment manipulation of the target-encoding task.

How might these findings be explained? One possibility is that the nontarget items in Experiment 1 were simply forgotten. That is, the "deeply" studied targets may have given rise to so much retroactive interference that the nontargets were inaccessible. The subjects in Experiment 1 may, therefore, have correctly excluded a large proportion of the nontargets because these items were misclassified as new words. To rule out this possibility, we ran a behavioral study on 6 additional subjects. This study replicated Experiment 1 exactly, with the exception that the subjects were required to exclude items from Study Block 2 (previously the targets) and to treat Block 1 items as targets. Mean classification accuracy for the latter items was $86 \%$, against a new-item false alarm rate of $3 \%$. It is, therefore, extremely unlikely that memory for nontargets in Experiment 1 was so poor that they were in general mistaken for new items.

In light of the evidence identifying the left parietal ERP effect as a correlate of recollection (see the introduction), we interpret the absence of a nontarget left parietal effect in Experiment 1 as reflecting a failure to recollect these items. As was argued in the introduction, it is, in principle, possible to correctly classify nontargets in an exclusion task in the absence of recollection, 
so long as information specifying the source of target items is recollected reliably. To do this, it is necessary merely to exclude an item if it fails to elicit information diagnostic of the target source. According to this argument, the failure of nontargets to elicit a left parietal effect in Experiment 1 reflects the adoption of the above strategy; the subjects classified targets on the basis of information retrieved about their encoding context and classified nontargets largely on the basis of the absence of such information. Indeed, upon debriefing, the majority of the subjects $(11 / 16)$ reported that they had adopted just this strategy. By contrast, only $3 / 16$ subjects reported attempting to use the strategy in Experiment 2, the remainder claiming to have based exclusion decisions on retrieval of the nontarget source.

The finding of a robust left parietal effect for nontargets in Experiment 2 suggests that source information associated with both targets and nontargets was recollected in this experiment. This finding is understandable on the assumption that when memory for the target source is poor, the failure to retrieve this information no longer serves as a reliable basis for classifying an item as a nontarget. Hence, recollection of nontarget source information is now required for these items to be excluded.

The recollection of target information at the expense of nontarget information in Experiment 1 could have depended on any one of several mechanisms (Anderson \& Bjork, 1994), of which two in particular seem plausible candidates. First, the failure to recollect nontarget items could have arisen because of cue bias (Anderson \& Bjork, 1994). According to this possibility, the subjects adopted a retrieval orientation (Robb \& Rugg, 2002; Rugg \& Wilding, 2000) that, while optimizing the processing of test items as cues for the recollection of target information, made these items ineffectual as cues for nontarget recollection.

The second possibility, and the one we believe to be most likely, is that the absence of a nontarget left parietal effect in Experiment 1 reflects attentional bias (Anderson \& Bjork, 1994). By this account, nontarget source information was retrieved in both experiments but was attended to only in Experiment 2 (see Dywan et al., 2002, Dywan et al., 1998, and Dywan et al., 2001, for similar accounts). This possibility is consistent with other findings suggesting that the left parietal effect is sensitive to the task relevance of retrieved information. Specifically, the magnitude of the effect is markedly greater when it is elicited in the direct test of recognition memory, rather than in indirect tests, such as semantic classification, when episodic retrieval is incidental to the task (Duzel et al., 1999; Paller, Kutas, \& McIsaac, 1995; Rugg \& Wilding, 2000; but see Curran, 1999). Rugg and Wilding argued that these findings may reflect not so much the failure to retrieve study information in an indirect task, as the failure to allocate processing resources to the information once retrieved (cf. Rugg, Fletcher, Frith, Frackowiak, \& Dolan, 1997).
To the extent that the foregoing account is correct, it could be argued that it is inappropriate to treat the absence of a left parietal effect to nontargets in Experiment 1 as evidence of a failure to recollect. By this argument, if nontarget source information was retrieved in both experiments, it makes no sense to say that in only one experiment was the information "recollected." The validity of this argument depends on one's preferred definition of "recollection." If the definition encompasses both the retrieval of episodic information and its employment in the conscious control of behavior (e.g., Jacoby \& Kelley, 1992), a failure to make use of retrieved information is indeed the equivalent of a failure to recollect. This would not necessarily be the case from the perspective of a more phenomenological definition of recollection (e.g., Gardiner \& Java, 1993). It is important to note, however, that regardless of the definition adopted, the present findings highlight the fragility of a key assumption underlying the use of the exclusion task to assess recollection in the context of tests of recognition memory. Even when they receive "standard" exclusion instructions that emphasize the utility of retrieving nontarget source information, subjects may make differential use of this information, depending on the accessibility of target information. ${ }^{3}$

The question arises as to why excluded nontargets elicited a parietal old/new effect in the studies of Wilding and Rugg (1997) and Cycowicz et al. (2001), but not in the present study or those of Dywan et al. (2002; Dywan et al., 1998; Dywan et al., 2001). According to the account given above, the answer lies, at least partially, in the relative saliences of target and nontarget source information. Another important factor, however, might be the distinctiveness of the target and the nontarget study contexts. Both in the present study and in Dywan et al. (2002; Dywan et al., 1998; Dywan et al., 2001), target and nontarget items were presented in separate study phases. In Wilding and Rugg (1997) and Cycowicz et al. (2001), by contrast, the two classes of items were intermixed within a single study phase. Thus, it may be that the adoption of a retrieval bias that favors one of two sources is facilitated by temporal segregation of the relevant encoding episodes.

The probability of correct target classification was significantly lower in Experiment 2 than in Experiment 1 . This finding indicates that, as was intended, the subjects experienced greater difficulty in detecting targets in the second experiment than in the first. Perhaps as a consequence of the greater difficulty of target recollection in Experiment 2, the subjects appear to have been more willing to classify items as targets on the basis of their familiarity, as reflected by the higher false alarm rate to new items in that experiment.

Unlike the false alarm rate for new items, the rate for nontargets did not vary across experiments but, instead, remained constant at about $17 \%$. It is fairly straightforward to account for these errors in Experiment 2: One 
need only make the assumption, inherent to the process dissociation procedure, that when recollection failed, the subjects sometimes endorsed items as targets on the basis of their familiarity. It is harder, however, to account for the exclusion errors in Experiment 1. Here, the newitem false alarm rate was near zero and, according to the account of the ERP findings given above, items should have been endorsed as targets only when the target source was recollected. This being so, one might have expected the nontarget false alarm rate in the first experiment to have been lower than that in Experiment 2. One possibility is that target endorsements were sometimes still based on familiarity in Experiment 1, but only when familiarity was very high (accounting for the low new-item false alarm rate in that experiment). This, combined perhaps with the occasional "misrecollection" of nontargets, could account for the nontarget false alarms observed in the first experiment. The more lax criterion adopted for familiarity-based target endorsements in Experiment 2 would, by itself, have led to a greater nontarget false alarm rate than that in Experiment 1 . This effect would, however, have been offset by the beneficial effects of recollecting both target and nontarget source information. In sum, the behavioral data can be accounted for in a manner compatible with the proposal that nontarget source information was recollected in Experiment 2 only. ${ }^{4}$

\section{REFERENCES}

Anderson, M. C., \& BJork, R. A. (1994). Mechanisms of inhibition in long term memory. In D. Dagenbach \& T. H. Carr (Eds.), Inhibitory processes in attention, memory, and language (pp. 265-325). San Diego: Academic Press.

Curran, T. (1999). The electrophysiology of incidental and intentional retrieval: ERP old/new effects in lexical decision and recognition memory. Neuropsychologia, 37, 771-785.

Curran, T. (2000). Brain potentials of recollection and familiarity. Memory \& Cognition, 28, 923-938.

Cycowicz, Y. M., Friedman, D., \& Snodgrass, J. G. (2001). Remembering the color of objects: An ERP investigation of source memory. Cerebral Cortex, 11, 322-334.

Donaldson, D. I., \& RugG, M. D. (1999). An event-related study comparing associative recognition and associative recall. Cognitive Brain Research, 8, 1-16.

Duzel, E., Cabeza, R. Picton, T. W., Yonelinas, A. P., Scheich, H., Heinze, H. J., \& Tulving, E. (1999). Task-related and item-related brain processes of memory retrieval. Proceedings of the National Academy of Sciences, 96, 1794-1799.

Duzel, E., Vargha-Khadem, F., Heinze, H. J., \& Mishin, M. (2001). Brain activity evidence for recognition without recollection after early hippocampal damage. Proceedings of the National Academy of Sciences, 98, 8101-8106.

Duzel, E., Yonelinas, A. P., Mangun, G. R. Heinze, H. J., \& TulVING, E. (1997). Event-related brain potential correlates of two states of conscious awareness in memory. Proceedings of the National Academy of Sciences, 94, 5973-5978.

Dywan, J., Segalowitz, S. J., \& Arsenault, A. (2002). Electrophysiological response during source memory decisions in older and younger adults. Brain \& Cognition, 49, 322-340.

Dywan, J., Segalowitz, S. J., \& Webster, L. (1998). Source monitoring: ERP evidence for greater reactivity to nontarget information in older adults. Brain \& Cognition, 36, 390-430.
Dywan, J., Segalowitz, S. J., Webster, L., Hendry, K., \& Harding, J. (2001). Event-related-potential evidence for age-related differences in attentional allocation during a source monitoring task. Developmental Neuropsychology, 19, 99-120.

Friedman, D., \& Johnson, R., JR. (2000). Event-related potential (ERP) studies of memory encoding and retrieval: A selective review. Microscopy Research \& Technique, 51, 6-28.

GARDINER, J. M., \& JAVA, R. I. (1993). Recognition memory and awareness: An experiential approach. European Journal of Cognitive Psychology, 5, 337-346.

Greenhouse, G. W., \& Geisser, S. (1959). On methods in the analysis of repeated measures designs. Psychometrika, 49, 95-112.

JACOBY, L. L. (1991). A process dissociation framework: Separating automatic from intentional uses of memory. Journal of Memory \& Language, 30, 513-541.

JACOBY, L. L., \& Kelley, C. M. (1992). Unconscious influences of memory: Dissociations and automaticity. In D. Milner \& M. Rugg (Eds.), The neuropsychology of consciousness (pp. 201-233). London: Academic Press.

KuČERA,H., \& FrancIS, W. N. (1967). Computationalanalysis of presentday American English. Providence, RI: Brown University Press.

MANDLER, G. (1980). Recognizing: The judgment of previous occurrence. Psychological Review, 87, 252-271.

Maratos, E. J., \& RugG, M. D. (2001). Electrophysiological correlates of the retrieval of emotional and non-emotional context. Journal of Cognitive Neuroscience, 13, 877-891.

McCARthy, G., \& Wood, C. C. (1985). Scalp distributions of eventrelated potentials: An ambiguity associated with analysis of variance models. Electroencephalography \& Clinical Neurophysiology, 62, 203-208.

Paller, K. A., Kutas, M., \& McIsaAc, H. K. (1995). Monitoring conscious recollection via the electrical activity of the brain. Psychological Science, 6, 107-111.

Roвb, W. G. K., \& RugG, M. D. (2002). Electrophysiological dissociation of retrieval orientation and retrieval effort. Psychonomic Bulletin \& Review, 9, 583-589.

RugG, M. D., \& Allan, K. (2000). Event-related potential studies of memory. In E. Tulving \& F. I. M. Craik (Eds.), The Oxford handbook of memory (pp. 521-537). Oxford: Oxford University Press.

Rugg, M. D., Fletcher, P. C., Frith, C. D., Frackowiak, R. S. J., \& Dolan, R. J. (1997). Brain regions supporting intentional and incidental memory: A PET study. NeuroReport, 8, 1283-1287.

Rugg, M. D., Herron, J. E., \& Morcom, A. M. (2002). Electrophysiological studies of retrieval processing. In L. R. Squire \& D. L. Schacter (Eds.), Neuropsychology of memory (3rd ed., pp. 154-165). New York: Guilford.

Rugg, M. D., Mark, R. E., Walla, P., Schloerscheidt, A. M., Birch, C. S., \& Allan, K. (1998). Dissociation of the neural correlates of implicit and explicit memory. Nature, 392, 595-598.

RugG, M. D., \& Wilding, E. L. (2000). Retrieval processing and episodic memory. Trends in Cognitive Neurosciences, 4, 108-115.

Schloerscheidt, A. M., \& RugG, M. D. (1997). Recognition memory for words and pictures: An event-related potential study. NeuroReport, 8, 3281-3285.

Smith, M. E. (1993). Neurophysiological manifestations of recollective experience during recognition memory judgements. Journal of Cognitive Neuroscience, 5, 1-13.

Spencer, K. M., Vila Abad, E., \& Donchin, E. (2000). On the search for the neurophysiological manifestation of recollective experience. Psychophysiology, 37, 494-506.

Tendolkar, I., Schoenfeld, A., Golz, G., Fernandez, G., Kuhl, K. P., Ferszt, R., \& Heinze, H. J. (1999). Neural correlates of recognition memory with and without recollection in patients with Alzheimer's disease and healthy controls. Neuroscience Letters, 263, 45-48.

Trott, C. T., Friedman, D., Ritter, W., Fabiani, M., \& Snodgrass, J. G. (1999). Memory for temporal source: Event-related potentials reveal age-related differences in prefrontal functioning. Psychology \& Aging, 14, 390-413.

WILDING, E. L. (2000). In what way does the ERP parietal old/new ef- 
fect index recollection? International Journal of Psychophysiology, 35, 81-87.

Wilding, E. L., \& Rugg, M. D. (1996). An event-related potential study of recognition memory with and without retrieval of source. Brain, 119, 889-905.

Wilding, E. L., \& RUGG, M. D. (1997). Event-related potentials and the recognition memory exclusion task. Neuropsychologia, 35, 119-128.

\section{NOTES}

1. The unequal numbers of items in the nontarget and the target blocks is a legacy of the fact that these studies form part of a series in which, for reasons irrelevant here, the earlier experiments employed unequal numbers of items in each of two study blocks. Since this aspect of the design was common to both experiments, it cannot account for the between-experiment differences in nontarget ERPs that were observed.

2. Inspection of Figure 1A shows that the ERPs elicited at the left parietal electrode by new items appear to differ across experiments. An ANOVA of the mean amplitudes of the 500- to 800-msec latency region of these ERPs failed, however, to give rise to a significant effect of experiment $[F(1,30)=2.88]$.

3 . A referee pointed out that our conclusion that nontargets were recollected in Experiment 2 was predicated on the assumption that the left parietal old/new effect is an exhaustive index of recollection. As we note in the text, whether the effect is considered to be such an index is to some extent dependent on one's definition of recollection; for us, recollection occurs when episodic information is both retrieved and attended to. Even if the left parietal effect should prove not to be an exhaustive index of recollection so defined, this would not negate the conclusion that nontargets in an exclusion task engage different retrieval processes, depending on the memorability of the targets. Given their weakest interpretation, the findings indicate that nontarget "recollection" can be subserved by processes sufficiently distinct to have dissociable neural correlates, raising the question of whether these processes are functionally equivalent. In addition, the findings would suggest that although the same processes subserved the recollection of targets and nontargets in Experiment 2, recollection of the two classes of item was subserved by different processes in Experiment 1 .

4. We thank John Wixted for suggesting this account of the behavioral data.

(Manuscript received July 31, 2001; revision accepted for publication May 17, 2002.) 